\title{
MANAGEMENT OF CLASS II FURCATION DEFECTS IN DOGS USING COMBINATION OF PROPOLIS AND NANOBONE GRAFT
}

\author{
Marwa Ibrahim*, Nesma M Khalil ${ }^{* *}$ and Rania A Fahmy*
}

\begin{abstract}
Background: Periodontal regeneration using complementary and alternative medicine has gained considerable attention recently. Propolis is a resinous hive product collected by honey bees from exudates and buds of plants and mixed with wax and bee enzymes.

Objective: The aim of this study was to evaluate the effect of propolis as bone graft substitute in the management of experimental grade II furcation defects, and to compare its effect to nanobone and to Propolis/nanobone mixture.

Material and Methods: Sixteen critical-sized furcation defects on the buccal surface of mandibular third and fourth premolars were surgically created in twelve dogs and divided into three groups. Group I; defects were filled with Propolis, Group II; defects were filled with nanohydroxyapatite graft and Group III; defects were filled with a combination of Propolis/ nanohydroxyapatite graft. Histologically and histomorphometric analysis of newly formed interradicular bone height and percentage were performed after one and three months.

Results: After one month; the three experimental groups revealed the features of early periodontal tissues regeneration including cementum, newly formed bone with inserted newly formed PDL fibers. The propolis group showed the highest bone height and bone surface area. After three months; denser bone occupying larger surface area of the furcation defect were noted especially in the propolis group.

Conclusion: The addition of nanobone to propolis showed better results than nano bone alone especially at early healing stage. However, it didn't show better results than the use of propolis alone.
\end{abstract}

KEY WORDS: Propolis, Alveolar Bone loss, Graft, Nanobone, Furcation.

* Assistant Professor, Department of Periodontology, Oral medicine, Diagnosis and Radiology, Faculty of Dentistry, Alexandria University, Alexandria, Egypt.

** Lecturer, Department of Oral Biology, Faculty of Dentistry, Alexandria University, Egypt. 


\section{INTRODUCTION}

Periodontal disease is a chronic inflammatory disease of the supporting structures of the teeth. As it proceeds, it advances to periodontal ligament loss and severe destruction of alveolar bone which may lead to tooth loss. The prevalence of periodontal diseases is about $20-50 \%$ with higher incidence in adolescents and adults ${ }^{1}$. Therefore, considerable attention is focused on periodontal regenerative procedures. A wide variety of grafting materials have been utilized in treating furcation defects caused by periodontal disease. However, the search for natural products have been gaining much attention lately. Apitherapy, an example of complementary and alternative medicine, is the medical use of bee products such as honey, propolis and bee venom. Egyptian propolis (bee glue) has recently become a subject of increasing interest. Propolis is a resinous hive product collected by honey bees from exudates and buds of plants and mixed with wax and bee enzymes. ${ }^{1,2}$

Propolis has a diverse range of biological properties, including anti-carcinogenic ${ }^{2}$, antioxidant ${ }^{3}$, antibacterial, antiviral and antifungal effects ${ }^{4}$, anti-inflammatory and immunomodulatory. ${ }^{5}$ In dentistry, propolis have been tested as a root canal disinfectant and has shown favorable outcomes against Enterococcus faecalis and C. albicans ${ }^{6,7}$. It has also been used in endodontic therapy and as a storage media with promising results ${ }^{8,9}$. Propolis maintains the viability of PDL in avulsed teeth and was able to preserve cells for up to 168 hour and maintains its regenerative potential ${ }^{10}$. Propolis have been shown to stimulate dentine regeneration and dental pulp stem cells when used for pulp capping ${ }^{11}$. Propolis was also found to have a stimulatory effect on bone formation through inhibiting osteoclastic activity and promoting osteoblastic activity when administered systemically ${ }^{12}$.

* ARTOSS GmbH Company, Germany

** Sigma Pharmaceutical Industries, Egypt
In a novel study in 2018 Zohery et al. ${ }^{13}$ examined the use of propolis as bone graft substitute in experimental grade II furcation defects and obtained favorable results regarding periodontal regeneration comparable to that obtained by nanohydroxyapatite graft. Nanohydroxyapatite graft materials are nanosized ceramics with better osseointegrative properties and quick resorbtion 14, 15. Nanohydroxyapatite has been shown to stimulate differentiation of PDL cells, and expression of BMP-2 ${ }^{16}$. Moreover, it stimulates osteoblasts in early periodontal repair stages ${ }^{17}$.

As reported by Zoheri el al. ${ }^{13}$ it is of great interest to report similar regenerative potential of propolis being a natural product, cheap and readily available- to that obtained by nanohydroxyapatite graft material.

Objective: The aim of the present work was to further investigate the potential of propolis as bone graft substitute and to examine the combined effect of Propolis and nano-hydroxyapatite material in grade II furcation defects in dog model.

\section{MATERIAL AND METHODS}

A comparative study was carried out on a total of twelve adult male mongrel dogs (Canis familiars) aged from 18 to 24 months. An adaptation period of four weeks was allowed before the beginning of the study. The study protocol was approved by the animal ethical committee of Alexandria University under the number IRB 00010556- IORG 0008839.

\section{Materials}

NanoBone graft material* was used to manage furcation defects. Propolis powder** was obtained by using the content of Biopropolis capsules. Each capsule contains $400 \mathrm{mg}$ pure Egyptian propolis. The contents of each capsule was mixed 
with two drops of saline using the pipette plastic $3 \mathrm{ml}$-sized dropper to obtain a moldable mix to manage furcation defects. Biocollagen membrane* was used to cover the grafted defects.

\section{Methods}

The study included three groups, each comprising sixteen surgically created critical-sized furcation defects on the buccal surface of each mandibular third and fourth premolars (P3, P4) in twelve dogs. Group I defects were filled with Propolis. Group II defects were filled with nanohydroxyapatite graft. Group III defects were filled with a combination of Propolis/ nanohydroxyapatite graft. All defects were covered with a collagen membrane.

\section{Surgical procedure}

All surgical procedures were performed under general anesthesia using intramuscular injection of $0.1 \mathrm{ml}$ ketamine hydrochloride (Bayer Inc. Canada) and $0.05 \mathrm{ml}$ xylazine hydrochloride (Alfas an Inc., Holland) per kg body weight. Mucoperiosteal flap was elevated using sulcular incision. Surgically created class II furcation defects on the buccal surface of the mandibular third and fourth premolars (P3, P4) of $3 \mathrm{~mm}$ depth $\mathrm{x} 5 \mathrm{~mm}$ height using carbide surgical burs were done in each dog bilaterally. ${ }^{17} \mathrm{In}$ four dogs a split mouth design with GTR approach was conducted in which defects of the left side were filled with propolis while nanohydroxyapatite bone graft (NanoBone) was used in the right side.

In another four dogs a combination of propolis and nanohydroxyapatite bone graft was placed in the left side while the right side received nanohydroxyapatite bone graft. In the remaining four dogs the propolis/ nanohydroxyapatite combination was placed in the right side while the left side received propolis alone (Table 1). Four furcation defects were created in the lower second premolar and left unfilled as negative controls for histological evaluation. Only collagen membrane was used to cover the defects as classical GTR technique. Histological examination was done for 6 dogs after one month and the other $6 \operatorname{dogs}$ after three months. At the apical end of each defect, two reference notches were created on the mesial and distal roots to serve as reference points for histologic examination. Root planing followed by root conditioning using tetracycline was performed. Propolis powder (Sigma Pharmaceutical Industries, Egypt) was obtained by using the content of Biopropolis capsules. Each capsule contains 400 mg pure Egyptian propolis. The contents of each capsule was mixed with two drops of saline using the pipette plastic $3 \mathrm{ml}$-sized dropper to obtain a moldable mix. Biocollagen membrane (BioTECK Company, Italy) was used to cover the grafted defects extending $2 \mathrm{~mm}$ around the created defects. Then flap repositioning with tension free closure was performed.

\section{Postoperative management}

Intramuscular Ampicillin ${ }^{* *}$ and Brufen $600 \mathrm{mg}^{* * *}$ administered for all animals in the first day. Then for the subsequent week, the medications were mixed with the dogs' food. Dogs were fed soft diet in the postoperative period to reduce the possibility of local trauma to the surgical sites. The experimental sites were observed to evaluate the gingival health and suture line closure until suture removal.

\section{Animals Euthanization}

An overdose thiopental sodium injection were given intravenous for six dogs were after one month and the other six dogs after three months. The mandible was dissected and cuts into two halves then preserved in $10 \%$ neutral buffered formalin for histological preparation.

\footnotetext{
* BioTECK Company, Italy

** Eipico, Egypt

*** Abbot GmbH, Germany
} 
TABLE (1) The allocation of defects for the tested graft materials

\begin{tabular}{|l|l|l|}
\hline Number of dogs & Left side & Right side \\
\hline 4 Dogs & Propolis & Nanobone \\
1 month $(2$ dogs $)$ & & \\
3 month $(2$ dogs $)$ & & Nanobone \\
\hline 4 Dogs & Propolis / & \\
1 month $(2$ dogs $)$ & nanobone & Propolis / \\
3 month $(2$ dogs $)$ & & nanobone \\
\hline $\begin{array}{l}4 \text { Dogs } \\
1 \text { month }(2 \text { dogs })\end{array}$ & Propolis & \\
\hline month $(2$ dogs $)$ & & \\
\hline
\end{tabular}

\section{Specimen preparation}

The specimens were fixed in $10 \%$ neutral buffered formalin, rinsed in distilled water, then decalcified in $10 \%$ EDTA. The specimens were dehydrated in ascending grades of alcohol, cleared in xylene and finally embedded in paraffin wax. Serial mesio-distal sections were cut and stained with haematoxylin and eosin stain using the conventional method ${ }^{18}$.

\section{Histomorphometric analysis}

Morphometric evaluation was done for each specimen using the (Image J 1.46r) software. Two precalibrated blinded examiners performed the measurements and the mean of their readings were calculated. From each specimen, 5 mesiodistal sections at different standardized depths were obtained. In each section, one photograph was taken using the same magnification power. In each photograph two parameters were calculated:

\section{Height of newly formed interradicular bone}

A horizontal line was drawn between the apical ends of the two notches in the interradicular dentin. Another straight line was drawn perpendicular to the previous line and extend till the bifurcation. This line was used to set a scale of $5 \mathrm{~mm}$ on the photograph to convert pixels to millimetres by choosing set scale from analyse tab.
Another straight line was drawn from the apical end of the 2 notches till the coronal end of the newly formed bone and its length was measured using Image $\mathrm{J}$ by choosing measure from analyse tab. The same procedure was repeated in each of the 5 sections in each specimen and the mean length was obtained. The same procedure was repeated in all specimens in each group.

\section{Mean percentage of surface area of newly formed inter-radicular bone.}

In each photograph, 3 rectangles with standardized dimensions were drawn in the furcation defect area and their surface area were calculated. In each rectangle, the bone marrow spaces was traced using wand tracing tool and their surface area was calculated. These two measurements were subtracted to obtain the area occupied only by bone. The results were expressed as percentage values (the proportion of area occupied only by bone in relation to the total area of the standard rectangle). The same procedure was repeated in each of the 5 sections in each specimen and the mean was obtained. The previous steps were repeated in all specimens in each group.

\section{Statistical analysis}

Histomorphometric measurements were described using range (minimum and maximum), mean, standard deviation and median. ANOVA was used to assess differences among groups ( $\mathrm{n}=16$ defect) followed by Tukey post hoc test. Analysis was done using SPSS version 22.0. Significance level was set at the $5 \%$ level.

\section{RESULTS}

\section{Histological results}

The histological observation of the negative control defects at 1 (2 defects) and 3 (2 defects) months revealed no regenerative process and the defects were only filled with granulation tissue. 


\section{After one month}

Histological examination of the specimens obtained at one month postoperatively in the three experimental groups revealed the features of early periodontal tissues regeneration. These features included, newly formed bone with inserted newly formed PDL fibers. Group I (propolis) showed relatively more amount of new bone formation in comparison to other groups. In addition, in both group I (propolis) \& group III (propolis/ nanobone) denser \& well oriented PDL fibers were seen (Figs 1and 2).

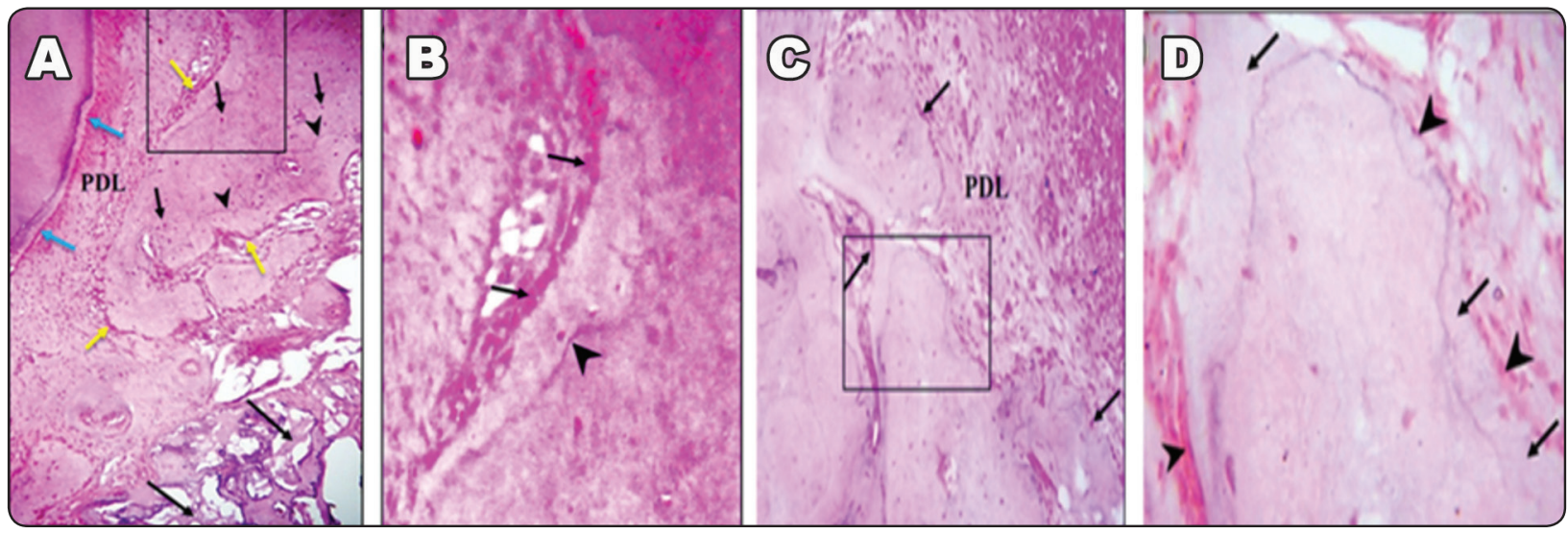

Fig. (1) Light micrograph (LM) of propolis group I and nanobone group II at one month: A: Showing the newly formed bone and the adjacent propolis remnants (long arrows). The bone exhibits regularly distributed osteocytes (short arrows) and reversal lines (arrow heads) which indicate continuous bone remodeling. The bone surface is covered by a continuous layer of osteoblasts (yellow arrows). The adjacent newly formed PDL fibers appears dense. A continuous layer of cementoblast (blue arrows) cells can be seen covering the root surface. B: Higher magnification of the previous micrograph inset showing a layer of plump osteoblasts (arrows) that can be seen covering the bone surface which reflect their activity and darkly stained reversal line (arrow head). C: Showing the regenerated bone adjacent to the newly formed PDL. Osteoblasts (arrows) can be seen covering the bone surface. D: Higher magnification of the previous micrograph inset showing the newly formed bone covered by a layer of osteoid (arrows). A layer of osteoblasts (arrow heads) can be seen covering the active bone surface. (H\&E A,C: x100, B,D: x400).
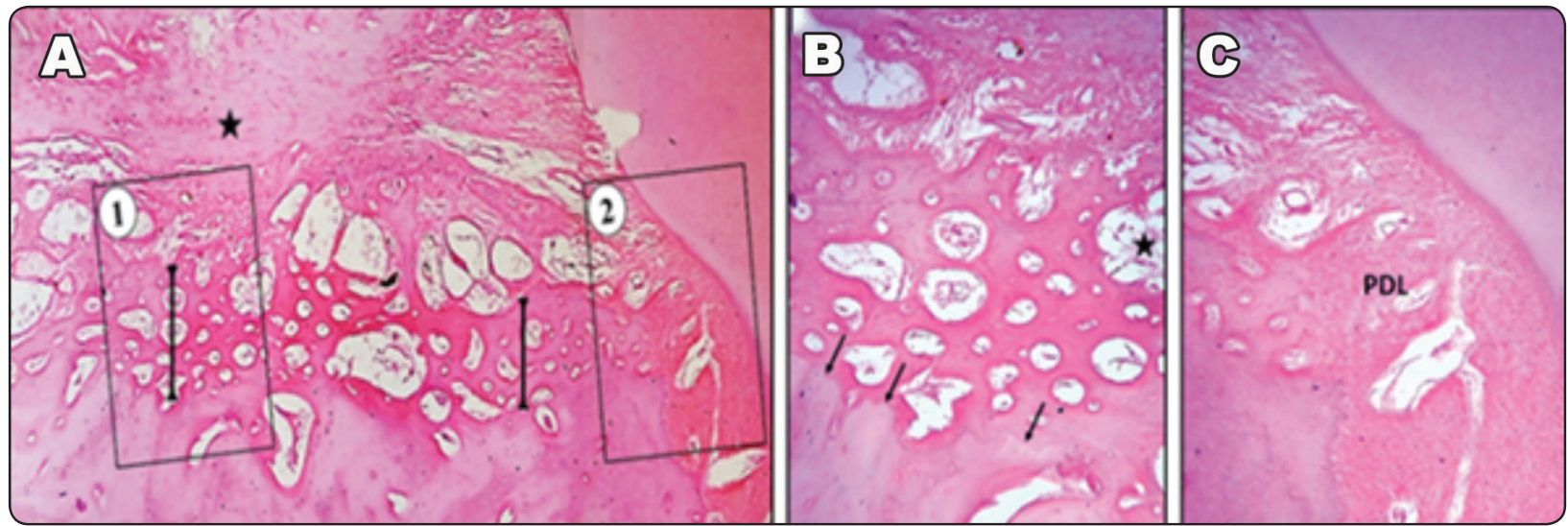

Fig. (2) Compound Light micrograph LM of group III (Propolis / nanobone) at one month: A: Showing the newly formed bone (I) at the interradicular area. The newly formed trabeculae can be seen extending from the old bone at its coronal end. Dense fibrous tissue (star) can be seen coronal to the new bone. B\&C: Higher magnification of the previous micrograph insets $1 \& 2$ respectively. (B): Shows the organization of the newly formed bone mass surrounding remnant of the nano-bone (star). Line of demarcation (arrows) can be clearly seen between old bone and newly formed bone. (C): Shows dense, well organized PDL fibres adjacent to the newly formed bone. (H\&E A: x40, B\&C: x100). 


\section{After three month}

Light microscopic examination of the specimens obtained from the 3 months' groups revealed the formation of more dense bone occupying larger surface area of the furcation defect especially in group I (propolis) in comparison to one month results of all groups, with almost complete osteointegration with the native bone. Dense PDL fibers were seen extending between the newly formed bone \& cementum. Cementoblasts and plump-looking osteoblasts were also seen covering the newly formed hard tissues (Figs. 3 and 4).

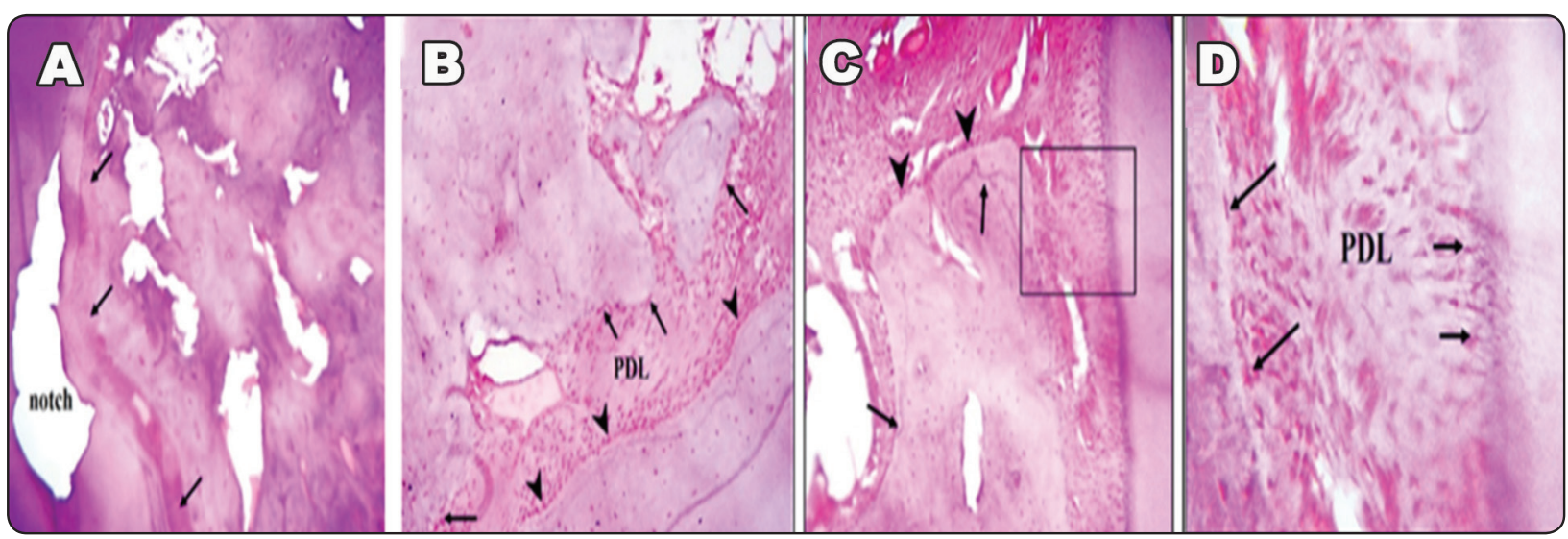

Fig. (3) Light micrograph LM of propolis group I and nanobone group II at three month: A: Showing the density of the newly formed bone at the interradicular region near the notch area and the adjacent regenerated PDL (arrows). Note the absence of line of demarcation between the old and new bone. B: Shows the organization of the regenerated periodontium at the healing area. Note the arrangement of osteoblasts (arrows), cementoblasts (arrow heads) and PDL fibers. C: Showing the regenerated periodontal tissue at the bifurcation area. The alveolar bone is dense with numerous reversal lines (arrows) at its coronal end. Note the outstanding density of osteoblasts especially at the alveolar crest (arrow heads). D: Higher magnification of the previous micrograph inset showing the orientation of osteoblasts (long arrows), cementoblasts (short arrows) and the intervening PDL fibers. (H\&E A\&B\&C: x100, D: x400).

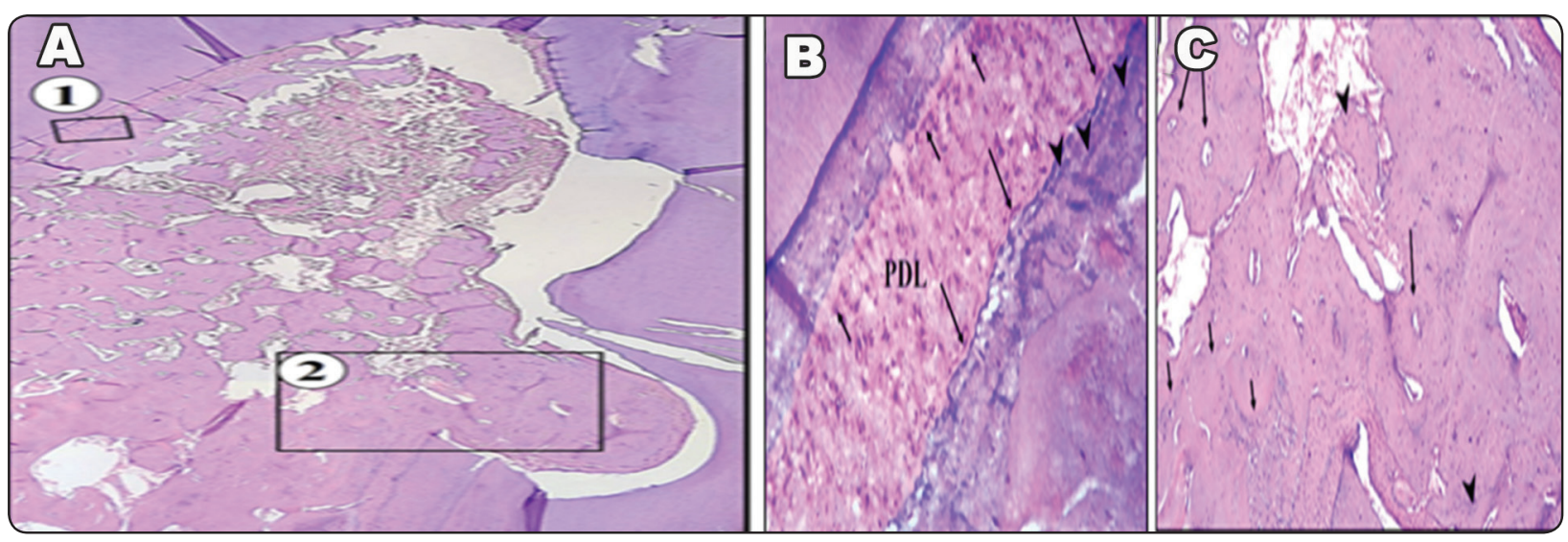

Fig. (4) Light micrograph LM of group III (Propolis / nanobone) at three months: A: Showing the regenerated periodontal tissues at the bifurcation area. B \& C are higher magnification of insets $1 \& 2$ respectively. B: Shows the density and orientation of PDL fibers in the regenerated area. Cementoblasts (short arrows) \& osteoblasts (long heads) are seen lining the root and bone surface respectively. Note the numerous resting lines (arrow heads) which can be clearly seen in the bundle bone giving it its characteristic lamellate structure. C: Shows complete osteointegration between the old \& newly formed bone (short arrows) at the notch area. Multiple osteons (long arrows) and reversal lines (arrow heads) can be seen. (H\&E A: x40, B: $x 400, C: x 100)$. 


\section{Histomorphometric results}

\section{Height of newly formed interradicular bone}

The height of the newly formed interradicular bone of the three studied groups at both one and three months' intervals are summarized in table (2) by means and standard deviation. At one month, propolis group showed the highest value $(4.44 \pm 0.25)$ followed by propolis/nanobone group and nanobone group, where the values were $(4.36 \pm 0.31$ and $4.22 \pm 0.17)$ respectively. A significant difference was noted between propolis and nanobone group $\left(\mathrm{p}_{1}=0.01\right)$. However, no significant differences were observed between propolis \& propolis/nanobone $\left(\mathrm{p}_{2}=0.99\right)$. The difference between nanobone and propolis/nanobone was also not significant $\left(\mathrm{p}_{3}=0.71\right)$.

At three-month interval, the three groups were very close to each other, where the propolis/ nanobone group showed the highest value (4.70 $\pm 0.47)$ followed by propolis group $(4.67 \pm 0.43)$ and the nanobone group $(4.61 \pm 0.41)$. Regarding the studied groups, no significant difference was found $(\mathrm{P}=0.69)$.

\section{Mean percentage of newly formed inter-radicular bone surface area}

The percentage of newly formed bone surface area in different studied groups at one and three month intervals are shown in table (3) by means and standard deviation. At one month, there was no significant difference between the three studied groups in mean percentage of bone surface area where $\mathrm{p}<0.5$. Propolis group showed the highest value $(76.2 \pm 6.1)$ followed by propolis/nanobone group (76.01 \pm 6.8) and finally nonbone group (75.9 \pm 6.2$)$. At three months, propolis group showed the highest value $(90.5 \pm 5.7)$ followed by propolis/ nanobone group $(85.38 \pm 6.1)$ and finally nonbone group (81.7 \pm 5.8$)$. A statistical significant was detected between the three groups $(\mathrm{p}=0.002)$.

TABLE (2): Comparison between the three studied groups regarding the height of newly formed interradicular bone

\begin{tabular}{|c|c|c|c|c|c|}
\hline Observational Period & $\begin{array}{c}\text { Propolis } \\
\text { Group I }\end{array}$ & $\begin{array}{c}\text { Nanobone } \\
\text { Group II }\end{array}$ & $\begin{array}{c}\text { Propolis/ Nanobone } \\
\text { Group III }\end{array}$ & P value & F \\
\hline 1 month (Mean \pm SD) & $4.44 \pm 0.25$ & $4.22 \pm 0.17$ & $4.36 \pm 0.31$ & $0.04^{*}$ & 3.50 \\
\hline 3 months (Mean \pm SD) & $4.67 \pm 0.43$ & $4.61 \pm 0.41$ & $4.70 \pm 0.47$ & 0.69 & 0.38 \\
\hline & P1 $=0.01^{*}$ & P2=0.99 & P3 $=0.71$ & & \\
\hline
\end{tabular}

TABLE (3): Comparison between the three studied groups regarding the percentage of the newly formed bone at the two observational periods

\begin{tabular}{|c|c|c|c|c|c|}
\hline Observational Period & $\begin{array}{c}\text { Propolis } \\
\text { Group I }\end{array}$ & $\begin{array}{c}\text { Nanobone } \\
\text { Group II }\end{array}$ & $\begin{array}{c}\text { Propolis/ Nanobone } \\
\text { Group III }\end{array}$ & P value & F \\
\hline 1 month (Mean \pm SD) & $76.2 \pm 6.1$ & $75.9 \pm 6.2$ & $76.01 \pm 6.8$ & 0.99 & 0.009 \\
\hline 3 months (Mean \pm SD) & $90.5 \pm 5.7$ & $81.7 \pm 5.8$ & $85.38 \pm 8.9$ & 7.07 \\
\hline & $\mathrm{P} 1=0.53$ & $\mathrm{P} 2=0.96$ & $\mathrm{P} 3=0.96$ & \\
\hline
\end{tabular}




\section{DISCUSSION}

Propolis is a natural nontoxic material that has many properties and has been used widely in the medical and dental field ${ }^{19}$. This lead to the concept that propolis may be helpful in periodontal regeneration. Nanohydroxyapatite is bone substitute that had shown relevant regenerative capacity in previous studies ${ }^{15}$.

In the current study we assessed periodontal regeneration in class II furcation defect using propolis mixed with nanohydroxyapatite bone substitute.

New bone formation was more pronounced in propolis \& propolis/nanobone group as confirmed by histologic and histomorphometric analysis. Similar to our findings, Boudra et al. ${ }^{20}$ showed that propolis enhanced the regenerative potential of allograft leading to better bone formation. Additionally, previous study ${ }^{16}$ showed that when combining alveolex (containing 10\% propolis) with rhBMP-2 improvement in bone regeneration was observed in calvarial defects.

The bone regenerative capability of propolis could be due to its modulatory effect on type I and III collagen as well as increasing the accumulation of chondroitin sulphate and hyaluronic acid thus enhancing tissue regeneration ${ }^{21}$. Furthermore, the antioxidant effect of Propolis boosts the healing process ${ }^{22}$.

In the current study, a continuous layer of osteoblasts covering the bone surface were seen both in propolis \& propolis/nanobone group. This is in agreement with Meimandi-Parizi et al. ${ }^{23}$ who observed increase in osteoblasts and osteocytes after using demineralized bone matrix scaffold with propolis in radial bone defect in rats comparied to other groups without propolis.

Serarslan et al. ${ }^{24}$ stated that caffeic acid phenethyl ester (CAPE; one of the flavonoids present in propolis) can also stimulate the process of wound healing. It can affect receptor activator of nuclear factor kappa ligand/osteoprotegerin (RANKL/ OPG) signaling leading to increase in the survival rate of osteoblasts while inhibiting osteoclasts ${ }^{25}$.

Moreover, it has been suggested that propolis has positive effects on bone metabolism through its antioxidant properties ${ }^{23}$. Reactive oxygen species (ROS) which are generated by oxidative stress can exert a negative effect on bone biology by inhibition of osteoblast differentiation and upregulation of osteoclast differentiation and function ${ }^{26}$. Uçan et al. ${ }^{27}$ found that local and systemic administration of CAPE enhances bone formation in calvarial bone defect comprised to untreated groups.

Our results showed organized constant rows of cementoblast-like cells and dense periodontal ligament fibers in the studied group which are in agreement with Gjertsen et al. ${ }^{28}$ who observed that propolis has enhanced the metabolic activity and proliferation of PDL cells.

Regarding the nanohydroxyapatite group in our work, high osteoblastic activity was observed reflected by thick osseous trabeculae with many remodeling lines. This comes in agreement with previous studies ${ }^{15}$ who observed high osseogenic properties of nanohydroxyapatite graft. The nanorough surface of the graft material may additionally enhance cellular adhesion and proliferation.

The almost absence of demarcating lines that distinguish between the newly formed and original bone was observed in all studied groups. This could reflect the maturity of bone with the potent osteogenic ability of both examined materials.

The histomorphometric results of the ongoing study showed comparable results in all groups regarding the interradicular bone height and the percentage of the newly formed bone.

Regarding the percentage of the newly formed bone in the current work, all groups showed similar bone fill after 1 month, however, the propolis group 
showed more bone fill after three months. Boudra et al. ${ }^{20}$ showed that the use of graft material covered with propolis accelerate the osteoconductive and osteoinductive process. This is similar to our findings that the combination of nanobone with propolis showed more bone formation than using nanobone alone. However, in our study the combined used of propolis/ nanobone did not show enhanced effect than propolis alone.

\section{CONCLUSION}

The combination of nanobone and propolis showed better results that nanobone alone. This could be explained by the surface topography of nanobone which acts as a reservoir for propolis, and allows continuous delivery of the propolis in the regenerated area. However, the combination of nanobone and propolis did not show better results than propolis alone.

Conflict of interest: None to declare.

\section{REFERENCES}

1. Nazir MA. Prevalence of periodontal disease, its association with systemic diseases and prevention. Int J Health Sci. 2017;11(2):72.

2. Szliszka E, Czuba ZP, Bronikowska J, Mertas A, Paradysz A, Krol W. Ethanolic extract of propolis augments TRAILinduced apoptotic death in prostate cancer cells. Evid Based Complementary Altern Med.. 2011;2011.

3. Teixeira EW, Negri G, Salatino A, Stringheta PC. Seasonal variation, chemical composition and antioxidant activity of Brazilian propolis samples. Evid Based Complementary Altern Med.. 2010;7(3):307-15.

4. Kujumgiev A, Tsvetkova I, Serkedjieva Y, Bankova V, Christov R, Popov S. Antibacterial, antifungal and antiviral activity of propolis of different geographic origin. J Ethnopharmacol 1999;64(3):235-40.

5. Orsatti C, Missima F, Pagliarone A, Bachiega TF, Búfalo M, Araújo Jr J, et al. Propolis immunomodulatory action in vivo on Toll-like receptors 2 and 4 expression and on pro-inflammatory cytokines production in mice. Phytother Res. 2010;24(8):1141-6.
6. Kayaoglu G, Ömürlü H, Akca G, Gürel M, Gençay Ö, Sorkun K, et al. Antibacterial activity of Propolis versus conventional endodontic disinfectants against Enterococcus faecalis in infected dentinal tubules. J Endod. 2011;37(3):376-81.

7. Sinha DJ, Garg P, Verma A, Malik V, Maccune ER, Vasudeva A. Dentinal tubule disinfection with propolis \& two extracts of azadirachta indica against candida albicans biofilm formed on tooth substrate. Open Dent J 2015;9:369.

8. Meto A, Bimbari B, Shytaj K, Özcan M.Anti-Inflammatory and Regenerative Effects of Albanian Propolis in Experimental Vital Amputations. Eur J Prosthodont Restor Dent 2016;24(3):145-51.

9. Babaji P, Melkundi M, Devanna R, Suresh B, Chaurasia VR, Gopinath P. In vitro comparative evaluation of different storage media (hank's balanced salt solution, propolis, Aloe vera, and pomegranate juice) for preservation of avulsed tooth. Eur J Dent. 2017;11(1):71.

10. Awawdeh L, Haimour RN, Al-Jundi SH, Al-Qaoud K. Human periodontal fibroblasts viability stored in Custodiol ${ }^{\circledR}$, coconut water, and propolis. An ex vivo study. Dent Traumatol. 2018.

11. AhangariZ,Naseri M,Jalili M, Mansouri Y,Mashhadiabbas F, Torkaman A. Effect of propolis on dentin regeneration and the potential role of dental pulp stem cell in Guinea pigs. CELL J. 2012;13(4):223.

12. Toker H, Ozan F, Ozer H, Ozdemir H, Eren K, Yeler H. A morphometric and histopathologic evaluation of the effects of propolis on alveolar bone loss in experimental periodontitis in rats. J Periodontol. 2008;79(6):1089-94.

13. Zohery AA, Meshri SM, Madi MI, Rehim SSAE, Nour ZM. Egyptian Propolis compared to Nanohydroxyapatite graft in Treatment of Grade II furcation defects in dogs. J Periodontol. 2018; 89:1340-1350.

14. Regazzini P, Novaes Jr AB, De Oliveira PT, Palioto DB, Taba Jr M, de Souza SL, et al. Comparative study of enamel matrix derivative with or without GTR in the treatment of class II furcation lesions in dogs. Int J Periodontics Restorative Dent 2004;24(5).

15. Ghanaati S, Barbeck M, Willershausen I, Thimm B, Stuebinger S, Korzinskas T, et al. Nanocrystalline hydroxyapatite bone substitute leads to sufficient bone tissue formation already after 3 months: histological and histomorphometrical analysis 3 and 6 months following human sinus cavity augmentation. Clin Implant Dent Relat Res.. 2013;15(6):883-92. 
16. Pereira NT, Issa JPM, Do Nascimento C, Pitol DL, Ervolino E, Da Cunha MR, et al. Effect of alveolex on the bone defects repair stimulated by rhBMP-2: Histomorphometric study. Microsc Res Tech. 2012;75(1):36-41.

17. Bayani M, Torabi S, ShahnazA, Pourali M. Main properties of nanocrystalline hydroxyapatite as a bone graft material in treatment of periodontal defects. A review of literature. Biotechnol Biotechnol Equip 2017;31(2):215-20.

18. Drury R, Wallington E. Preparation and fixation of tissues. Carleton's histological technique. 1980;5:41-54.

19. Khurshid Z, Naseem M, Zafar MS, Najeeb S, Zohaib S. Propolis: a natural biomaterial for dental and oral healthcare. J Dent Res Dent Clin Dent Prospects 2017; 11(4):265.

20. Boudra A, Hamdi M, Amara K. Role of propolis in osteointegration enhancement in allograft autoclaved implanted in femur of dogs. J VET MED 2014;5(2).

21. Olczyk P, Komosinska-Vassev K, Winsz-Szczotka K, Stojko J, Klimek K, Kozma EM. Propolis induces chondroitin/ dermatan sulphate and hyaluronic acid accumulation in the skin of burned wound. J Evid Based Complementary Altern Med.. 2013;2013.

22. Callaway DA, Jiang JX. Reactive oxygen species and oxidative stress in osteoclastogenesis, skeletal aging and bone diseases. J Bone Miner Metab2015;33(4):359-70.
23. Meimandi-Parizi A, Oryan A, Sayahi E, Bigham-Sadegh A. Propolis extract a new reinforcement material in improving bone healing: An in vivo study. Int. J. Surg. 2018;56:94101 .

24. Serarslan G, Altuğ E, Kontas T, Atik E, Avci G. Caffeic acid phenetyl ester accelerates cutaneous wound healing in a rat model and decreases oxidative stress. Clin Exp Dermatol2007;32(6):709-15.

25. Tolba MF, El-Serafi AT, Omar HA. Caffeic acid phenethyl ester protects against glucocorticoid-induced osteoporosis in vivo: Impact on oxidative stress and RANKL/OPG signals. Toxicol. Appl. Pharmacol. 2017;324:26-35.

26. Bai X-c, Lu D, Bai J, Zheng H, Ke Z-y, Li X-m, et al. Oxidative stress inhibits osteoblastic differentiation of bone cells by ERK and NF- $x$ B. Biochem. Biophys. Res. Commun.2004;314(1):197-207.

27. Uçan M, Koparal M, A ğaçayak S, Gunay A, Ozgoz M, Atilgan $\mathrm{S}$, et al. Influence of caffeic acid phenethyl ester on bone healing in a rat model. J Int Med Res 2013; 41(5):1648-54

28. Gjertsen AW, Stothz KA, Neiva KG, Pileggi R. Effect of propolis on proliferation and apoptosis of periodontal ligament fibroblasts. Oral Surg Oral Med Oral Pathol Oral Radiol Endod 2011;112(6):843-8. 